\title{
VFF in MMU: Determination for Velocity of Fluid Flow in Multiphase Measurement Unit - Comparative Analysis
}

\author{
Dr. Edriss Eisa Babikir Adam, \\ Assistant Professor / EEE, \\ Mainefhi College of Engineering and Technology, \\ Mainefhi, Eritrea. \\ bonzoga20@gmail.com
}

\section{Prof. Sathesh, \\ Department of EEE,}

Eritrea Institute of Technology,

Eritrea.

sathesh4you@gmail.com

\begin{abstract}
The velocity measurement of liquid flow in a channel is a challenging task still. The chemical reaction and heat transfer condition are one of the internal elements of liquid for any process and production industries. Besides, the flow velocity is a significant factor to measure temperature in liquid flow. This research article reviews an overview of the velocity of fluid measurement techniques by advanced concepts in the multiphase measurement system. Based on luminescence properties, the velocity measurement is derived by large particle spectrum analysis due to laser excitation in the machine. This mathematical model analysis is used to measure the velocity of a fluid with the same particles of velocimetry. This development can be derived from the many changes of measurement factors in the heat transfer mechanism. The flowmeter design will be optimized with this mathematical proof for phosphor thermometry measurement technique. This research article contains phosphor thermometry for the measurement with implementing techniques and how this thermometry will be appropriated for temperature measurement in liquid flow. It gives the compare graphic representation for various work of temperature measurement in liquid flow of common aspects. The successful metric measurement can be ended by various intrinsic keys to the future development of the
\end{abstract}


Journal of Electrical Engineering and Automation (EEA) (2020)

Vol. 02/ No. 04

Pages: 168-180

https://www.irojournals.com/iroeea

DOI: https://doi.org/10.36548/jeea.2020.4.005

procedure. The velocity measurement performs by LDA and PIV methods. The advantages and limitations have been discussed for both the method at most recent.

Keywords: Velocity measurement, flowmeter concepts

\section{INTRODUCTION}

The flow is measured in a flowmeter for various industrial applications such as turbine rotation, fluid dynamics, many flow measurement units. The temperature is measuring in many flowmeters to protect from the burst in meter or inaccuracy [1]. Generally, this measurement can be ended with two named "A" \& "B" thermal sensors in the flow meter which is shown in figure 1. This thermal flowmeter can measure the temperature with the difference of two thermal sensor outputs [2]. Many protect units are available to build a strong thermo-wall for industrial temperature measurement systems. The electronic transmitter can be incorporated inside the connection head of the sensor [3]. This sensor has a signal conditioning circuit is located between the sensor place. The non-invasive velocity measurement techniques are as follows;

1. Laser Doppler Anemometry

2. Particle Image Velocimetry

3. Positron Emission Particle Tracking

4. Radioactive Particle Tracking

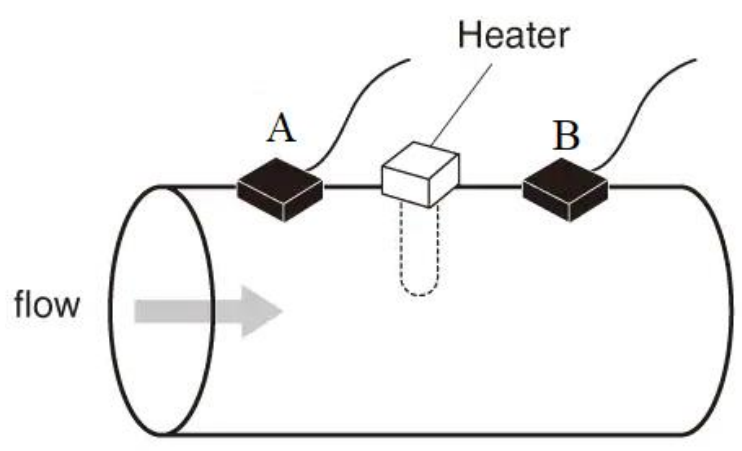

Figure 1 Invasive method of temperature measurement system in flowmeter

This is an invasive technique of measurement technique due to inserted probe as intrusive. The extra element is inserted to measure temperature which disturbs both temperatures as well as the flow of the liquid [4]. Due to some heavy bound solid particles will 
Journal of Electrical Engineering and Automation (EEA) (2020)

Vol. 02/ No. 04

Pages: 168-180

https://www.irojournals.com/iroeea

DOI: https://doi.org/10.36548/jeea.2020.4.005

damage the thermal sensor and solid flow will have disturbed easily. These two main major drawbacks of invasive techniques. But it is cost-wise very low-priced compared to noninvasive technique. The non-invasive technique is used to measure the temperature in the flowmeter without contact with a flowmeter to avoid damage to the thermal sensor [5]. The laser-based research for the measurement of temperature involves the electronic spectrum excitation of a particle by the light [6]. The author highlights advanced techniques non-invasive with state of art in temperature measurement in the flowmeter. Many process industries will opt non-invasive measurement technique which is used to measure the temperature without alarming flow in the container. This research article provides an overall idea about velocity measurement non-invasive method of comparison of two techniques of multiphase measurement [7]. The non-invasive methods are named as Laser-Doppler Anemometry (LDA), Particle Image Velocimetry (PIV), Positron Emission Particle Tracking (PEPT), Radioactive Particle Tracking (RPT) which is indicated in figure 2.

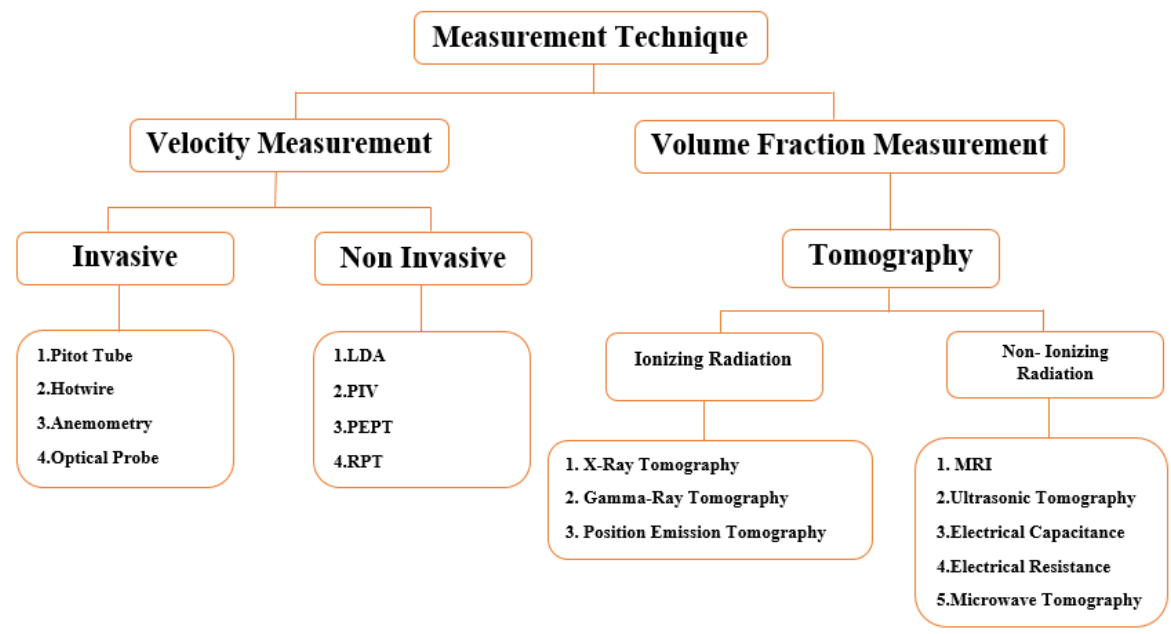

Figure 2 Classification of measurement Techniques

\section{ORGANIZATION OF THE RESEARCH}

The structure of the research article is organizing follows; Section 3 gives existing recent research papers on temperature measurement techniques for liquid flow. Section 4 discusses LDA and PIV methods to measure the velocity of fluid flow. Section 5 delivers a description of obtained results and discussion. The conclusion and the future task discusses in section 6 . 
Journal of Electrical Engineering and Automation (EEA) (2020)

Vol. 02/ No. 04

Pages: 168-180

https://www.irojournals.com/iroeea

DOI: https://doi.org/10.36548/jeea.2020.4.005

\section{PRELIMINARIES}

Initially, the fluid measurement was considered phosphor particles implementation for emission easily [8]. Miller et al performed liquid phase thermal measurement in a highly sensitive place of fluctuation temperature with consideration of heat and mass transfer study [9]. Allison et al introduces phosphor techniques on surfaces and got many advantages for the flow tracer method which is the temperature diagnosis process [10]. The phosphor particles provide temperature details as a function as a light scattering for laser measuring velocimetry. Usually, this phosphor consists of soil combination material like ceramic. The non-invasive methods are used to measure temperature in liquid flow without contact. Therefore, some display units' droplets and spray with the help of fast framing camera [11]. It was developed with image instantaneous measurement for temperature and velocity field of small motored [12]. The use of high-speed CMOS cameras was tested in a gas turbine film refrigeration system [13]. The measuring flow velocity is ended by laser Doppler velocimetry technique with the form of liquid droplets. Also, the flow velocity ends by particle image velocimetry with reactive flows. Many researcher's experiment point of view for this particle image velocimetry technique is domain based microscopic process. Based on non-invasive method measurement is using two cameras to obtain the flow details in the different angles at the outof-axis direction. The Rayleigh scattering technique is used to measure the temperature commonly in many research [14] [15]. The spectroscopy method is used to measure temperature and pressure in many combustion environments [16]. The sensor is sensing many details based on the specification of its, and which will construct in the form of encapsulated particles. These particles are synthesized by thermal dependant unit which is used to exchange the ion particles. This method can give by tracing measurement in liquid for temperature and velocity measurements in it [17] [18]. The 2D imaging sector consists of many UV excitation particles and measuring the demanded metrics.

\section{METHODOLOGIES}

Generally, the invasive methods are occupying more place in any devices to measure the temperature or velocity of the fluid. To get better accuracy the size of the probe should be reduced, therefore measurement may change at the point of measurement itself [19]. To avoid those complications non-invasive methods are preferable for a static mathematical model. The probe lifetime also very less in invasive technique due to dipped into hot liquid conditions. 
Journal of Electrical Engineering and Automation (EEA) (2020)

Vol. 02/ No. 04

Pages: 168-180

https://www.irojournals.com/iroeea

DOI: https://doi.org/10.36548/jeea.2020.4.005

\subsection{Particle Image Velocimetry (PIV)}

This method is the very basic optical-based technique through the laser light penetrating process. The particle image velocimetry is used to measure the overall displacement. To get the velocity map through the images in this method. The components are used in PIV systems is shown in figure 3. The process of the measurement as follows; take two images in a very short duration, process the images into some small pixels [20]. The small pixel performed by FFT algorithm and cross-correlation between both images at the same time. Then the overall displacement can be determined after taking inverse FFT of cross-correlation details. Here spatial resolution and speed of the process are very high due to using the FFT algorithm. This method is suffering from a laser intensity problem [21]. The spatial resolution is based on generating a pulse during the process. The experimental setup of PIV is showing in figure 4 .

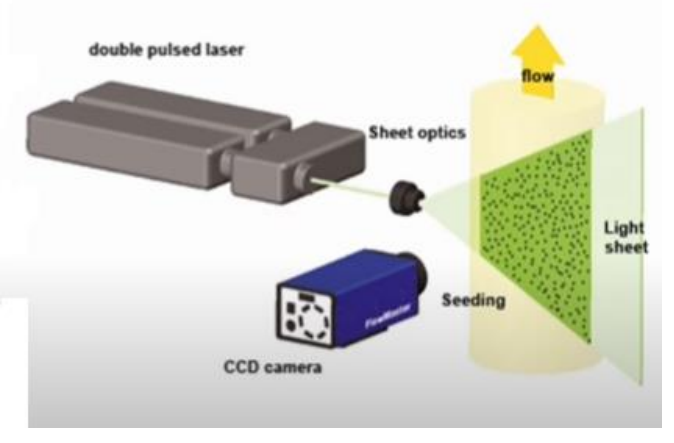

Figure 3 Components used in PIV

The laser, lens, tracer particle, camera, measurement setting with CPU and postprocessing software. The camera is high quality and the high-speed camera such as Charged Coupled Device (CCD) camera [22]. The synchronizer is used to synchronize the central processing unit and laser unit. The display unit is a camera setup for taking very short burst images from the fluid flow. 


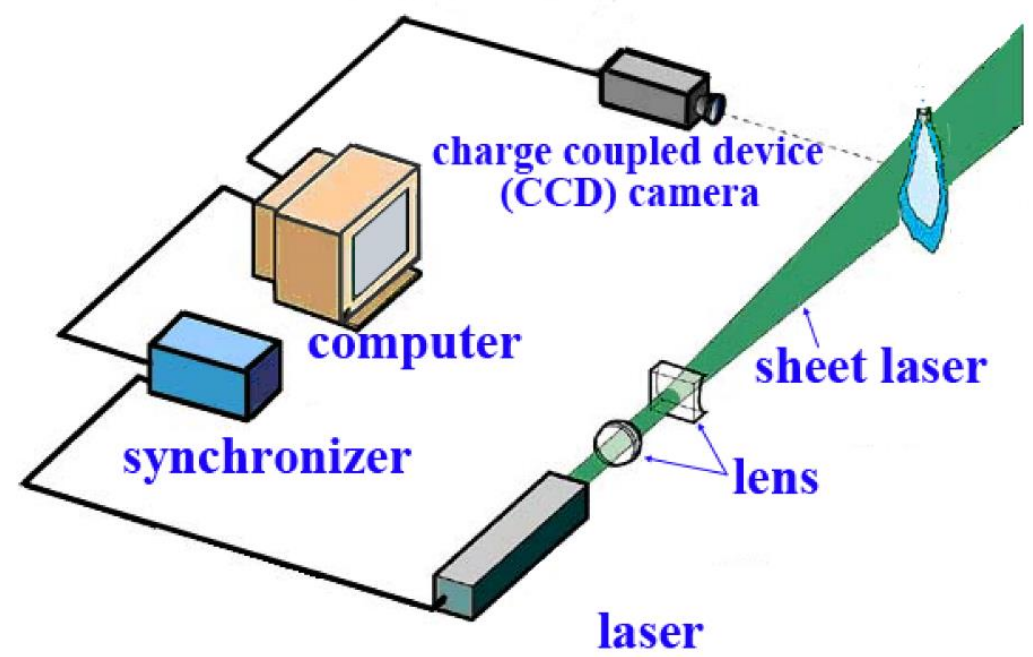

Figure 4 Block diagram of experiment setup of PIV

The post-processing software is used to get appropriate velocity fluid. Usually, the accuracy of the PIV is depending on tracer particles, light source, light sheet optics, and camera [23]. When we used small tracer particles in the process; the step response and follow the flow will be high accuracy. But large tracer particle in the process provides a very poor response in the accuracy of the process. Bu light scattering is very good during large particle used. It is reversed during small particle used [24][25]. The image quality is not good during the process when small particles are used which is shown in the result and discussion section in figure 6 . Therefore, the intensity of laser light should be increased. But it is harmful to surrounding measurement. This clarity is shown very well in the LDA method. So we have to use a highpower laser for the better quality of the image [26].

\subsection{Laser Doppler Anemometry}

LDA technique is suitable for many applications which are based on the non-invasive type method. Based on the Doppler effect, the device will measure the velocity of the fluid. It is detecting the fluid velocities by frequency shift of laser light which is coming from the laser light [27]. The laser light will pass through some medium which is going to measure. The light waves will be scattered with little particles. Therefore, the receiver will receive less amount of energy from the light sources. This difference can be measured and correlated with the signal from "TX" and "RX" of the devices. Then can be calculated this shift in the frequency with the moving object (here fluid) which is shown in figure 5. According to Doppler shift, 


$$
f_{D}=\frac{c}{\lambda}\left[\frac{v \cdot \hat{\jmath}-v \cdot \hat{c}}{c-v \cdot \hat{\jmath}}\right]
$$

Where $f_{D}$ is to be measured by measuring the incident frequency

Single beam laser Doppler anemometry as derived;

$$
f_{D}=\frac{2 \cdot v_{x}}{\lambda} \operatorname{Cos}(\beta) \operatorname{Sin}\left(\frac{\alpha}{2}\right)
$$

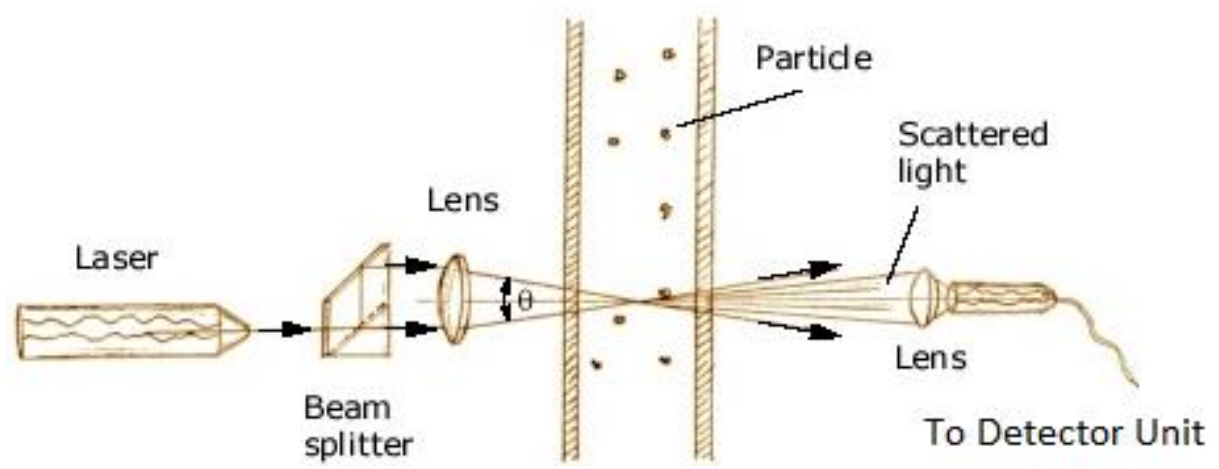

Figure 5 Experimental setup for Laser Doppler Anemometry

The linear velocity is measured by the LDA Doppler effect. The seed particles are small enough to measure the velocity. By focusing the beam very narrowly on an object that receives the frequency of the signal to the detector [28]. The contained object is moving; the frequency of the signal will be varied from the source of the signal. Now, this scattered light through the transparent wall generates the current in direct proportion to the absorption of the light energy. This shifting function of scattered light is proportional to the speed of the fluid [29]. To measure the Doppler effect in the frequency; it depends on the speed of the object and seating of the particle which velocity has to track. Also, it is depending on the direction of the particle motion from the source to the receiver which is shown in figure 6 . When measuring the direction of moving incident of light it will be negative and the Doppler effect is less [30] [31] [32].

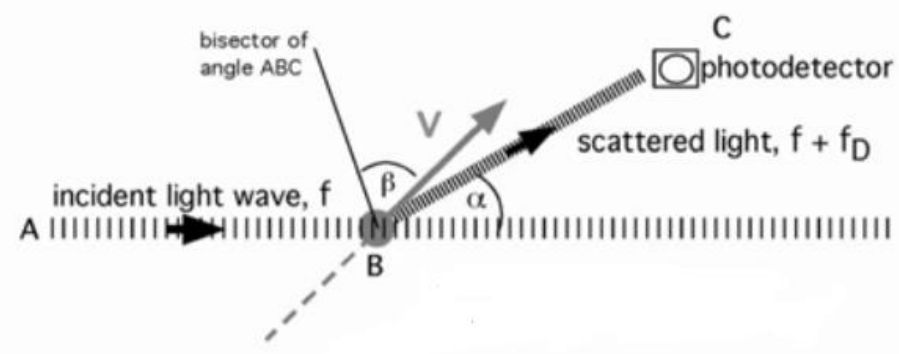

Figure 6 Particle scatters light through incident wave 
Journal of Electrical Engineering and Automation (EEA) (2020)

Vol. 02/ No. 04

Pages: 168-180

https://www.irojournals.com/iroeea

DOI: https://doi.org/10.36548/jeea.2020.4.005

If it is moving in the opposite direction, the Doppler effect will be high and intensity will be high. The way depends on the direction wavelength of light. Therefore, we have to choose the proper light sensor and set the appropriate wavelength of light in the direction of the detector [33][34]. This direction computes by the angle between light waves and the detector. As mentioned in the equation, the is the direction of particle movement and angle between denoted the velocity vector and bisector which is shown in figure 6 .

\section{RESULTS DISCUSSION}

Many systems are performing flow - dynamics research for the human body is doing by the LDA method. The LDA flowmetry process takes place within a scientific environment. This power laser penetrates inside the flow tube sufficiently and it is scattered through Doppler shift which is mentioned as an equation in the previous section. The calibration is not needed for this LDA method. The light is incidental on the moving object is denoted velocity in a particular direction. The photodetector is placed on the $\mathrm{C}$ axis which is shown in figure 5, but the wave is incidental provided no particle there will be certain particle will be recorded on this photodetector. Because of this particle velocity, the light incidental on the object will be scattered. The scattered light frequency can be calculated $\mathrm{f}+\mathrm{fD}$. Also, spatial time resolutions are high. In surrounding electronic components, this LDA method is capable of tracking for high fluctuation. The photodetector is used to convert from light energy into electrical for analysis. The sensor is tuned to the flow measurement with mentioned boundaries to flow direction. The optical unit is used to extract the signal from the scattered function. It is obtained $0.1 \%$ absolute accuracy for single-phase flow. But the absolute accuracy is diminishing for multiphase flow measurement gradually. 

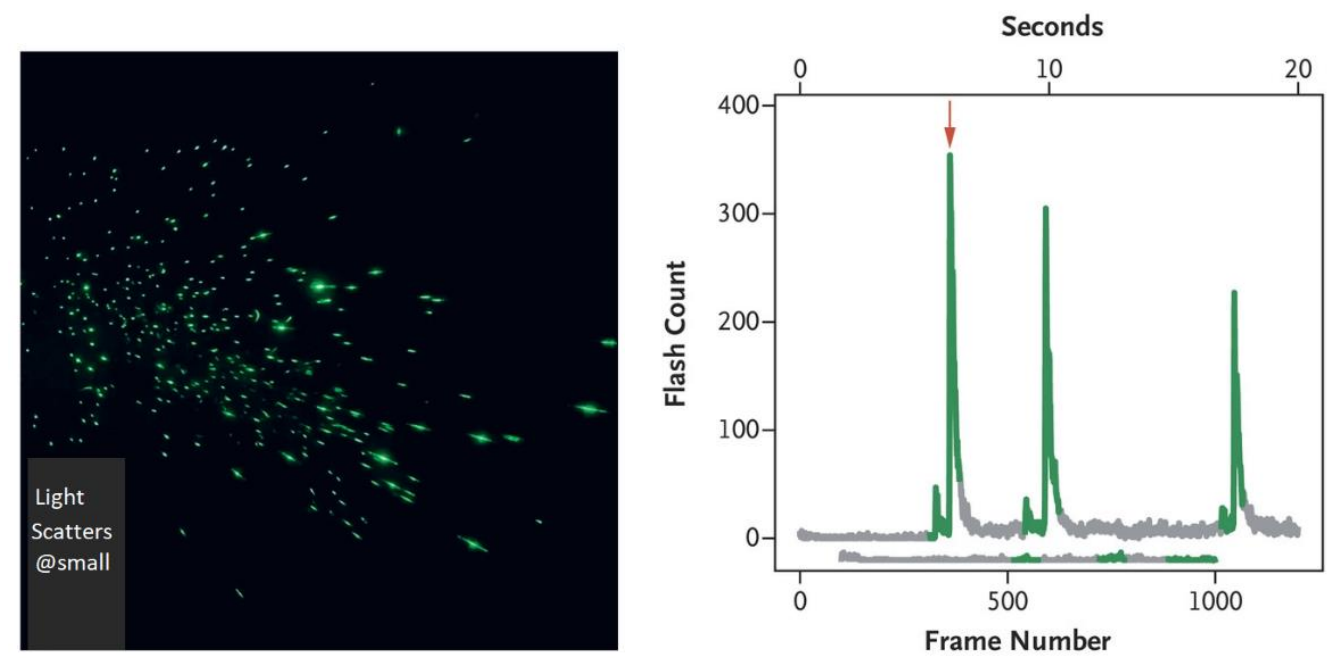

Figure 7 a) Light scattering at small particle b) camera frame click in small duration

This measurement is used to show the velocity of flow of fluid on the container with good accuracy compared to PIV. The PIV is applying for a wide range of flow monitoring in many flow control industries. The light scattering at small particle measurement by PIV shows in figure 7. The laser pulse clicks are delaying to capture the displacement of the trace function. Therefore, the tracer particles components are scattering more in the large duration time interval. This tracer particle can be adjusted and tuned by a high-power laser. Also, the interrogation area is very large. But it is having no significant velocity gradient within the area. Table 1 shows result obtained with parameters of both LDA and PIV methods.

Table 1 Results obtained from both methods

\begin{tabular}{|l|l|c|c|c|}
\hline S.No & PARAMETERS & LDA & \multicolumn{2}{|c|}{ PIV } \\
\hline 1 & Fluid Container Wall & Transparent & Transparent & $\begin{array}{c}\text { Mostly Non-invasive } \\
\text { property }\end{array}$ \\
\hline 2 & Scattering Waves & Random & $\begin{array}{c}\text { At particular } \\
\text { direction }\end{array}$ & $\begin{array}{c}\text { The direction is tuned by } \\
\text { small particles }\end{array}$ \\
\hline 3 & Resolution & Good & Low & $\begin{array}{c}\text { Improving by phase } \\
\text { volume fraction }\end{array}$ \\
\hline 4 & Absolute Accuracy & $\begin{array}{c}\text { Relative } \\
\text { High }\end{array}$ & Low & $\begin{array}{c}\text { The size of interrogation } \\
\text { area should be small }\end{array}$ \\
\hline
\end{tabular}


Journal of Electrical Engineering and Automation (EEA) (2020)

Vol. 02/ No. 04

Pages: 168-180

https://www.irojournals.com/iroeea

DOI: https://doi.org/10.36548/jeea.2020.4.005

\section{CONCLUSION}

The laser Doppler velocimetry method is used in many automation sectors for flow industries. The speed of solid objects can be measured by this method for example conveyor belts, a rotary encoder. This LDA is used in many large-scale industries such as in MEMS devices. It can be compared the performance of accelerometer devices for vibration. During the data analysis, the scattering particles are located randomly which leads to inaccuracy performance shortly. The arrangement of optical is very sensitive to system vibration. This process is needed a transparent container wall for measuring the velocity of fluids. To obtain better resolution and accuracy, the discrete phase volume fraction should be minimized at least $5 \%$. The change of wavelength of beam laser light is affecting based on particle travel speed which is called the Doppler effect. The LDA focuses on a small volume fluid container with small particles due to the random scattering effect. This analysis can be taken as our future work for great precision, and good resolution in further process.

\section{REFERENCES}

[1] Ojo AO, Fond B, van Wachem BGM, Heyes AL, Beyrau F. Thermographic laser doppler velocimetry. Opt Lett 2015;40(20):4759-62.

[2] Ojo AO, Fond B, Abram C, van Wachem BGM, Heyes AL, Beyrau F. Thermographic laser doppler velocimetry using the phase-shifted luminescence of bam:eu2p phosphor particles for thermometry. Opt Express 2017;25 (10):11833-43. doi: 10.1364/OE.25.011833.

[3] Omrane A, Juhlin G, Ossler F, Alden M. Temperature measurements of single droplets by use of laser-induced phosphorescence. Appl Opt 2004;43:3523-9.

[4] Omrane A, Santesson S, Alden M, Milsson S. Laser techniques in acoustically levitated micro droplets. Lab Chip 2004;4:287-91.

[5] Brubach J, Patt A, Dreizler A. Spray thermometry using thermographic phos- $€$ phors. Appl Phys B 2006;83:499-502.

[6] Kearney SP. Hybrid fs/ps rotational $\{\mathrm{CARS}\}$ temperature and oxygen measurements in the product gases of canonical flat flames. Combust Flame 2015;162 (5):1748-58. doi: 10.1016/j.combustflame.2014.11.036.

[7] Omenetto N, Benetti P, Rossi G. Flame temperature measurements by means of atomic fluorescence Spectrochimica. Spectrochimica Acta 1972;27:453-61. 
Journal of Electrical Engineering and Automation (EEA) (2020)

Vol. 02/ No. 04

Pages: 168-180

https://www.irojournals.com/iroeea

DOI: https://doi.org/10.36548/jeea.2020.4.005

[8] Nakatani N, Matsumoto M, Ohmi Y, Yamada T. Turbulence measurement by the pulse luminescence method using a nitrogen pulse laser. J Phys E 1977;10 (2):172.

[9] Miller WA, Keyhani M. The correlation of simultaneous heat and mass transfer experimental data for aqueous lithium bromide vectical falling film absorption. J Sol Energy Eng 2001;123:30-42. [25] Allison S, Garvey D, Cates M, Goedeke S, Gillies G, Hollerman W. On the use of phosphors for flow measurements. 11th international symposium on flow visualisation; 2004.

[10] Allison S, Garvey D, Cates M, Goedeke S, Gillies G, Hollerman W. On the use of phosphors for flow measurements. 11th international symposium on flow visualisation; 2004. [11] Omrane A, Sarner G, Ald € en M. 2D-temperature imaging of single droplets and sprays using thermographic phosphors. Appl Phys B 2004;79:431-4.

[12] Neal N, Jordan J, Rothamer D. Simultaneous measurements of in-cylinder temperature and velocity distribution in a small-bore diesel engine using thermographic phosphors. SAE Int J Engines 2013;6:19pp.

[13] Schreivogel P, Abram C, Fond B, Straußwald M, Beyrau F, Pfitzner M. Simultaneous khz-rate temperature and velocity field measurements in the flow emanating from angled and trenched film cooling holes. Int J Heat Mass Transf 2016;103:390-400.

[14] Zhao F-Q, Hiroyasu H. The applications of laser Rayleigh scattering to combustion diagnostics. Prog Energy Combust Sci 1993;19(6):447-85. doi: 10.1016/ 03601285(93)90001-U.

[15] Miles RB, Lempert WR, Forkey JN. Laser Rayleigh scattering. Meas Sci Technol 2001;12(5):R33.

[16] Eckbreth A. Laser diagnostics for combustion temperature and species. 2nd ed. Gordon and Breach; 1996.

[17] Someya S, Yoshida S, Li Y, Okamoto K. Combined measurement of velocity and temperature distributions in oil based on the luminescent lifetimes of seeded particles. Meas Sci Technol 2009;20:9pp.

[18] Someya S, Ochi D, Li Y, Tominaga K, Ishii K, Okamoto K. Combined two-dimensional velocity and temperature measurements using a high-speed camera and luminescent particles. Appl Phys B 2010;99:325-32.

[19] Alden M, Grafstr om P, Lundberg H, Svanberg S. Spatially resolved temperature $€$ measurements in a flame using laser-excited two-line atomic fluorescence and diode-array detection. Opt Lett 1983;8:241-3. 
Journal of Electrical Engineering and Automation (EEA) (2020)

Vol. 02/ No. 04

Pages: 168-180

https://www.irojournals.com/iroeea

DOI: https://doi.org/10.36548/jeea.2020.4.005

[20] Medwell P, Chan Q, Kalt P, Alwahabi T, Dally B, Nathan G. Development of temperature imaging using two-line atomic fluorescence. Appl Opt 2009;48:1237- 48.

[21] Mahmoud S, Nathan G, Medwell P, Dally B, Alwahabi Z. Simultaneous planar measurements of temperature and soot volume fraction in a turbulent nonpremixed jet flame. Proc Combust Inst 2015;35(2):1931-8. doi: 10.1016/j. proci.2014.06.122.

[22] Kaminski C, Engstrom J, Ald € en M. Quasi-instantaneous two-dimensional tem- perature measurements in a spark ignition engine using 2-line atomic fluorescence. Proc Combust Inst 1998;27:85-93.

[23] McMillin B, Palmer J, Hanson R. Temporally resolved, two-line fluorescence imaging of NO temperature in a transverse jet in a supersonic cross flow. Appl Opt 1993;32:7532-45.

[24] Seitzmann J, Hanson R. Two-line planar fluorescence for temporally resolved temperature imaging in a reacting supersonic flow over a body. Appl Phys B 1993;57:385-91.

[25] Bessler WG, Hildenbrand F, Schulz C. Two-line laser-induced fluorescence imaging of vibrational temperatures in a no-seeded flame. Appl Opt 2001;40 (6):748-56. doi: 10.1364/AO.40.000748.

[26] Bessler W, Schulz C. Quantitative multi-line no-lif temperature imaging. Appl Phys B 2004;78(5):519-33. doi: 10.1007/s00340-004-1421-x.

[27] Devillers R, Bruneaux G, Schulz C. Development of a two-line oh-laser-induced fluorescence thermometry diagnostics strategy for gas-phase temperature measurements in engines. Appl Opt 2008;47(31):5871-85. doi: 10.1364/ AO.47.005871.

[28] Schulz C, Sick V. Tracer-LIF diagnostics: quantitative measurement of fuel concentration, temperature and fuel/air ratio in practical combustion systems. Prog Energ Combust 2005;31:75-121.

[29] Kaiser S, Schild M, Schulz C. Thermal stratification in an internal combustion engine due to wall heat transfer measured by laser-induced fluorescence. Proc Combust Inst 2013;34:2911-9. doi: 10.1016/j.proci.2012.05.059.

[30] Luong M, Zhang R, Schulz C, Sick V. Toluene laser-induced fluorescence for incylinder temperature imaging in internal combustion engines. Appl Phys B 2008;91:669-75.

[31] Peterson B, Baum E, Bohm B, Sick V, Dreizler A. High-speed PIV and LIF imaging € of temperature stratification in an internal combustion engine. Proc Combust Inst 2013;34:365360. 
Journal of Electrical Engineering and Automation (EEA) (2020)

Vol. 02/ No. 04

Pages: 168-180

https://www.irojournals.com/iroeea

DOI: https://doi.org/10.36548/jeea.2020.4.005

[32] Peterson B, Baum E, Bohm B, Sick V, Dreizler A. Spray-induced temperature $€$ stratification dynamics in a gasoline direct-injection engine. Proc Combust Inst 2014: 1-9. doi: 10.1016/j.proci.2014.06.103.

[33] Koban W, Koch J, Hanson R, Schulz C. Oxygen quenching of toluene fluorescence at elevated temperatures. Appl Phys B 2005;80:777-84.

[34] Cundy M, Trunk P, Dreizler A, Sick V. Gas-phase toluene LIF temperature imaging near surfaces at $10 \mathrm{kHz}$. Exp Fluids 2011;1:1169-76. 